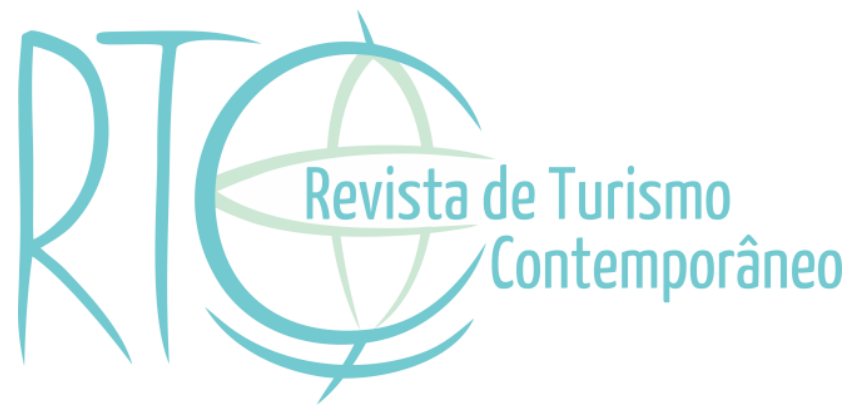

\title{
A hospitalidade de Pelotas/RS pela visão de quem não enxerga e aos passos de quem não caminha
}

\section{The hospitality of Pelotas/RS by the sight of those who do not see and the steps of those who do not walk}

Igor Moraes Rodrigues

Mestrando em Turismo na Universidade Federal do Paraná - UFPR, Curitiba/PR, Brasil

E-mail: igormoraesr2@gmail.com

\section{Sarah Marroni Minasi}

Doutoranda em Turismo e Hotelaria na Universidade do Vale do Itajaí - UNIVALI, Itajaí/SC, Brasil

E-mail: sarahminasi@gmail.com

\section{Alice Islabão Lopes}

Doutoranda em Memória Social e Patrimônio Cultural pela Universidade Federal de Pelotas

- UFPel, Pelotas/RS, Brasil

E-mail: aliceilopes@hotmail.com

\section{Luziara Souza da Silva}

Bacharel em Turismo pela Universidade Federal de Pelotas - UFPel, Pelotas/RS, Brasil

E-mail: luziarasouza@yahoo.com.br 


\section{RESUMO}

O objetivo proposto desta pesquisa é analisar a hospitalidade da cidade de Pelotas/RS na percepção das pessoas com deficiência visual e física (cadeirantes). Metodologicamente, esta pesquisa caracteriza-se por ser de natureza exploratória e descritiva, realizada por meio de pesquisa bibliográfica com abordagem qualitativa em que foram aplicados questionários com os sujeitos da pesquisa por e-mails e redes sociais Facebook e WhatsApp. Como principais resultados encontrados, identificou-se que o entendimento sobre hospitalidade de todos os sujeitos está relacionado ao bem receber-acolher. Para as pessoas com deficiência visual a questão do respeito com o visitante prevalece enquanto os sujeitos cadeirantes acrescentam a relação com a acessibilidade. No que tange à concepção de hospitalidade urbana e cidade hospitaleira, apesar das dimensões em comum, as falas das pessoas com deficiência visual estão mais relacionadas à identificação e envolvimento ativo do ser humano na cidade, enquanto as pessoas cadeirantes trazem à tona dimensões de acessibilidade física. Já no que diz respeito a Pelotas ser uma cidade hospitaleira, os sujeitos cadeirantes divergem sobre esta concepção apontando a (falta de) acessibilidade física como principal motivo enquanto todos os sujeitos com deficiência visual consideram Pelotas hospitaleira. Com os resultados desta pesquisa foram sistematizadas dimensões da cidade hospitaleira para pessoas com deficiências além de fomentar reflexões sobre hospitalidade e pessoas com distintos tipos de deficiência.

Palavras-chave: Turismo. Hospitalidade Urbana. Deficiência Visual. Cadeirantes. Pelotas/RS.

\section{ABSTRACT}

The aim proposed by this research is to analyze the hospitality of the city of Pelotas/RS in the perception of people with visual and physical disabilities (wheelchair users). Methodologically, this research is characterized by being of exploratory and descriptive nature, conducted through bibliographic research with a qualitative approach with questionnaires applied to the research subjects through e-mails and social networks Facebook and WhatsApp. The main results found that the understanding of hospitality of all subjects is related to good receive-acceptance. For people with visual impairment, the issue of respect for the visitor prevails, while wheelchair users add the relationship with accessibility. Regarding the concept of urban hospitality and hospitality city, despite the standard dimensions, the statements of the visually impaired are more related to the identification and active involvement of the human being in the city. Wheelchair users bring to surface dimensions of physical accessibility. As for Pelotas being a hospitable city, wheelchair users disagree on this concept, pointing out the (lack of) physical accessibility as the main reason. At the same time, all visually impaired individuals consider Pelotas hospitable. The results systematized dimensions of the hospitable city for people with disabilities, in addition to fostering reflections on hospitality and people with different types of disabilities.

Keywords: Tourism. Urban Hospitality. Visual Impairment. Wheelchair Users. Pelotas/RS. 


\section{INTRODUÇÃO}

Considerada um fenômeno social que se manifesta em contexto doméstico, comercial, virtual ou público, a hospitalidade é o ato humano de recepcionar, hospedar, alimentar e entreter pessoas temporariamente deslocadas de seu habitat (Camargo, 2003). Com isso, Silva (2015, p. 21) descreve que "ser hospitaleiro auxilia o turista deficiente ou não a se inserir na sociedade com mais segurança, percebendo que é aceito". Nesta perspectiva, a cidade enquanto lugar de hospitalidade, acolhimento, está relacionada aos estudos da hospitalidade pública, pois o espaço da hospitalidade urbana é, predominantemente, o espaço público. Porém, não se deseja que os espaços públicos sejam apenas acessíveis fisicamente, mas sim que sejam lugares de encontro, tolerância, de mistura e agradáveis, porque segundo Grinover (2007, p. 17) “antes mesmo que as pessoas é o próprio espaço público que nos recebe e transmite a atmosfera do lugar".

Sassaki (2003) aponta que a atividade turística surge como oportunidade para possibilitar a inclusão social de pessoas com deficiência. Mendes e Paula (2008) complementam que o lazer turístico além de ser potencial motivador da inclusão social, busca a ampliação da participação de todos no turismo. Já Martins (2008) defende que o turismo deve contribuir gradualmente para a formação de uma sociedade inclusiva e Mora (2012) acrescenta que o fator humano, tanto quanto o meio estrutural, é essencial para uma atividade turística acessível. A partir disso, faz-se importante relacionar a hospitalidade a essas questões de inclusão de pessoas com deficiências uma vez que o fator humano é primordial nos estudos e abordagens desta temática.

Com base nessa discussão teórica e a partir do interesse dos autores desta pesquisa pela relação das temáticas hospitalidade e pessoas com deficiências (tanto visual quanto cadeirantes) nas atividades turísticas, além da identificação de uma lacuna no que tange a produção científica que aborde esta interface, houve uma motivação e desejo pessoal em pesquisar e produzir conhecimento sobre este assunto.

Para isso, a pesquisa em questão trata de um estudo a respeito da hospitalidade pelotense na visão de quem não enxerga e aos passos de quem não caminha, ou seja, de pessoas com deficiência visual e de pessoas cadeirantes. Como sujeitos da pesquisa têm-se os participantes cegos da $3^{\text {a }}$ edição do Encontro Olho de Sogra e os membros cadeirantes do Grupo de Cadeirantes Núcleo da Luz vinculado à Fraternidade Cristã de Pessoas com Deficiência de Pelotas/RS. 
O Encontro Olho de Sogra é um evento criado por uma pessoa cega sendo pensado, organizado e planejado exclusivamente para pessoas com deficiência visual, com o propósito de apresentar o patrimônio histórico e cultural da cidade de Pelotas. O evento acontece por meio de atividades que exploram os sentidos da audição, tato, olfato e paladar, utilizando de recursos da audiodescrição (Rodrigues, 2019). A cidade de Pelotas é reconhecida nacionalmente pela produção de doces, bem como por sua história, recebendo certificação do Instituto do Patrimônio Histórico e Artístico Nacional (IPHAN) nas categorias patrimônio material e imaterial, pelo tombamento do Conjunto Histórico ${ }^{1}$ e pela tradição doceira, respectivamente (Peres, 2018). Já o Grupo de Cadeirantes Núcleo da Luz vinculado à Fraternidade Cristã de Pessoas com Deficiência de Pelotas/RS faz parte de um movimento ecumênico internacional que nasceu na França em 1942 e possui inúmeros núcleos espalhados pelo mundo com o objetivo de reunir pessoas com deficiência, as colocando em contato umas com as outras para promover a integração familiar, na comunidade, na sociedade, além de incentivar a prática de lazer destas pessoas (Pasped, [20--]).

Assim, este estudo possui como problema de pesquisa: Como a hospitalidade da cidade de Pelotas/RS é percebida por pessoas com deficiência visual e pessoas cadeirantes? Visando responder a problemática enunciada, esta pesquisa tem por objetivo geral analisar a hospitalidade da cidade de Pelotas/RS na percepção das pessoas com deficiência visual e das pessoas cadeirantes. Quanto aos objetivos específicos: apontar o entendimento dos sujeitos a respeito do tema hospitalidade; verificar o que torna uma cidade hospitaleira de acordo com suas percepções e identificar se eles consideram Pelotas uma cidade hospitaleira.

\section{INTERFACE ENTRE HOSPITALIDADE E PESSOAS COM DEFICIÊNCIAS NAS}

\section{ATIVIDADES TURÍSTICAS}

Diversos pesquisadores discorrem a respeito da origem da hospitalidade (Plentz, 2005). Para muitos autores a hospitalidade parte do pressuposto das relações estabelecidas entre anfitrião-visitante (Grinover, 2007; Severini, 2013; Perazzolo, Pereira \& Santos, 2013; Camargo, 2015). A interface entre as temáticas de turismo e hospitalidade acrescidas de abordagens sobre pessoas com deficiências é vista como uma relação complexa e necessária à construção da sociedade (Campos, 2008; Mendes \& Paula, 2008; Silva, 2015; Duarte, Pereira \& Lima, 2016). Assim, considerando a diversidade de abordagens sobre estudos de turismo e

\footnotetext{
${ }^{1} \mathrm{O}$ conjunto é formado por quatro praças (José Bonifácio, Coronel Pedro Osório, Piratinino de Almeida, Cipriano Barcelos), o parque Dom Antônio Zattera, a Chácara da Baronesa e a Charqueada São João (Instituto do Patrimônio Histórico e Artístico Nacional - IPHAN, 2018).
} 
hospitalidade, neste artigo priorizou-se por autores que buscam a interface conceitual entre tais temáticas com estudos sobre pessoas com deficiências.

Camargo (2004) afirma que a hospitalidade pode ser compreendida a partir de uma discussão sobre as relações humanas. Nesta perspectiva, a hospitalidade é considerada por Boff (2005) como uma das virtudes necessárias para a construção de um outro mundo possível, a partir do resgate do respeito, da tolerância, da convivência, da comensalidade e da própria hospitalidade. Já Dencker (2004) compreende a mesma como um ato social, essencial ao ser humano, que resulta na interação e troca com o outro.

Severini (2013) e Camargo (2015) em seus estudos sobre hospitalidade entendem que é o encontro entre anfitrião e hóspede em um determinado espaço. Camargo (2015) observa que aquele que recebe o outro, também pode ser hóspede em outras localidades, constituindose em um ciclo, no qual a ação humana assume papel primordial.

A hospitalidade para Campos (2008) é algo muito mais complexo, que consiste na união, na aproximação de culturas, costumes, que estabelece uma relação de troca de valores entre visitante e visitado. Silva (2015) entende que o ato de ser hospitaleiro está diretamente ligado ao turismo, porém não somente ao mesmo. A autora complementa que "ser hospitaleiro auxilia o turista deficiente ou não a se inserir na sociedade com mais segurança, percebendo que é aceito" (Silva, 2015, p. 21). Matheus (2002) acrescenta que a hospitalidade representa a base do laço social, pois tem como princípio opor-se à ideia de exclusão. A partir disto, Panosso Netto e Lohmann (2012) expõem que a máxima da hospitalidade é receber bem, não importa a quem [grifo nosso].

Sobre experiências urbanas, Dutra, Caldas, Pinheiro e Bastos (2017) assinalam que a hospitalidade urbana é o acolhimento e cortesia da cidade. Os autores pontuam que uma cidade hospitaleira é aquela que propicia vivências e interações com o outro e com o lugar, e quanto maior a possibilidade destas experiências, maior será a condição hospitaleira do espaço (Dutra et al., 2017). Ferraz (2013) aborda que o crescimento populacional associado à falta de infraestrutura urbana contribuiu para que as cidades deixassem de ser sinônimo de espaços de acolhimento e vínculo social. Para Severini (2013) as cidades de hoje e de ontem foram e continuam sendo produtoras de ideias, de conhecimento, elas são inovadoras.

Nesse sentido, é imprescindível que as cidades sejam inclusivas nas mais diversas atividades sociais, colaborando com essa ideia, Grinover (2007) percebe o acesso à cidade enquanto um direito de todos. $\mathrm{O}$ autor reforça essa complexidade das cidades dizendo que "a cidade deixa de ser um conceito estritamente geográfico, para se transformar em um símbolo complexo e inesgotável da experiência humana" (Grinover, 2007, p. 128). É importante que 
as cidades sejam espaços de inclusão social de pessoas com deficiências no sentido de permitir que estas vivenciem as inúmeras sensações e experiências que o espaço proporciona.

Grinover (2007, p. 153) afirma: "a única possibilidade de construir a hospitalidade pressupõe a capacidade de conhecer a cidade como ela é, sobretudo, de reconhecê-la como realidade". O autor ainda ressalta que a hospitalidade urbana não deve ser pensada como apenas prestações de serviços, e sim "enquanto virtude [...], princípio orientador de ações baseadas no respeito e no reconhecimento do outro" (Grinover, 2007, p. 17). Nesse contexto de receptivo turístico e prestadores de serviços, Santos e Perazzolo (2012) contribuem explicando que o receptivo turístico tende a se tornar cada vez mais humanizado, sendo denominado como "corpo coletivo acolhedor".

Tribe (2010) comenta que a pesquisa em turismo põe em primeiro plano algumas questões deixando outras intocadas. $\mathrm{O}$ autor aponta a existência de quatro áreas silenciadas na pesquisa em turismo e dentre tais áreas encontra-se o grupo de minorias o qual abrange as pessoas com deficiências (Tribe, 2010). Na interface entre as temáticas, Camargo (2019) explica que a hospitalidade pode ser considerada, atualmente, como um mecanismo para minimizar a exclusão. Cambiaghi (2007) destaca que um espaço hospitaleiro, inclusivo e acessível propicia a utilização e circulação irrestritas, integrando a todos e não apenas pessoas com alguma deficiência.

O Instituto Brasileiro de Geografia e Estatística - IBGE (2010) aponta que no Brasil existem mais de 45,6 milhões de pessoas com algum tipo de deficiência, representando 23,9\% da população. Conforme Duarte et al., $(2016$, p. 2) "se enquadram na categoria de pessoas com deficiência visual, tanto as que possuem baixa visão, como aquelas com cegueira total, congênita ou adquirida”. De acordo com Ribas (1985) a deficiência visual é considerada uma deficiência sensorial, assim como a auditiva. Pessoas com deficiência física (cadeirantes) são "as pessoas que apresentam grande perda ou perda total do movimento dos membros inferiores, necessitando, portanto, de equipamentos específicos para a sua locomoção" (Cantarelli, 1998, p. 4).

Darcy e Dickson (2009) mencionam que quase todas as pessoas, em algum momento de suas vidas, terão demandas específicas de acesso, seja isso permanente ou temporário como resultado de um acidente ou ferimento -, através do conhecimento de familiares ou amigos com demandas específicas de acesso ou, com alguém com quem estejam viajando.

Pensar no acolhimento, inclusão e na acessibilidade para pessoas com deficiência nos espaços se trata de um fenômeno recente. As primeiras discussões e debates mais significativos sobre estas temáticas tiveram início apenas no final dos anos 1990 (Mendes \& 
Paula, 2008). A falta de inclusão das pessoas com deficiências nas atividades sociais é muito pautada para alguns autores na questão da invisibilidade que essas pessoas tiveram no decorrer da história. Pereira, Degasperi e Couto (2018) abordam que

\begin{abstract}
pensar a pessoa com deficiência como um ser integral é antes de tudo colocá-la em um patamar de igualdade de oportunidades, reconhecendo a deficiência como uma característica identitária da mesma, deixando de lado a ideia de incapacidade, culturalmente adotada por muitos séculos, em que o abandono, a clausura e a vergonha fizeram com que milhares de pessoas vivessem à margem da vida e dos acontecimentos sociais (Pereira et al., 2018, p. 5).
\end{abstract}

Complementando a esta questão da invisibilidade, Luiz (2016) discorre que por muito tempo as pessoas com deficiências foram escondidas por seus familiares, por vergonha ou pelo instinto de proteção, o que corroborou para ausência de um planejamento citadino voltado para estes indivíduos. Darcy e Dickson (2009, p. 32) explicam que "embora a deficiência possa ter consequências dramáticas para o indivíduo, a deficiência não deve, por natureza, reduzir a participação de um indivíduo na comunidade em qualquer área de sua escolha".

Silva (2015) observa que as pessoas com deficiência de modo geral vêm se tornando cada vez mais exigentes e buscando seu espaço, inclusive nas atividades turísticas e de lazer. Sassaki $(2003,2006)$ cita que a atividade turística oportuniza a inclusão social e pressupõe um processo bilateral em que a sociedade e as pessoas com deficiência procuram se adaptar tendo em vista uma equiparação de oportunidades. O autor (2003) ainda destaca que é preciso permitir que as pessoas com deficiência possuam autonomia para se locomover, viajar e trabalhar. Para tanto, de acordo com Mendes e Paula (2008) é preciso disseminar o respeito e não estabelecer barreiras mediante as diferenças.

Medidas como as sancionadas pela Organização das Nações Unidas, em 1975, da Declaração dos Direitos das Pessoas Deficientes, dispositivos da Constituição Federal do Brasil, de 1988, entre outras referências no âmbito internacional e nacional, direcionam políticas que buscam garantir a todas as pessoas deficientes direitos básicos como: liberdade, saúde, educação, trabalho, cultura e lazer (Moreira, 2008). Entretanto, para Silva (2015) ainda é notável que os espaços urbanos necessitam de adaptações, capacitação do pessoal, qualificação nos serviços e atendimentos prestados para essas pessoas. Permitindo assim, que todos desfrutem com igualdade, autonomia e liberdade destas atividades de descontração ou até mesmo o simples fato de se locomover com segurança (Silva, 2015). 


\section{METODOLOGIA}

Para atingir aos objetivos propostos, metodologicamente a pesquisa caracteriza-se como sendo de natureza descritiva e exploratória, efetuada por meio de pesquisa bibliográfica e aplicação de questionários com perguntas abertas em uma abordagem qualitativa.

Sobre os sujeitos da pesquisa, a intenção foi de utilizar como sujeitos pessoas com deficiências (visuais e físicas) que fossem participantes de algum grupo, ou seja, não era a intenção que esses sujeitos fossem pesquisados de maneira isolada. A partir disto, as pessoas com deficiência visual são participantes da $3^{\text {a }}$ edição do Encontro Olho de Sogra e os sujeitos com deficiência física (cadeirantes) são membros do Grupo de Cadeirantes Núcleo da Luz, vinculado à Fraternidade Cristã de Pessoas com Deficiência de Pelotas/RS.

A $3^{\text {a }}$ edição do Encontro Olho de Sogra ocorreu em fevereiro de 2019 em Pelotas/RS contando com a presença de 13 participantes. Desta totalidade, nove participantes se dispuseram a colaborar com a pesquisa. Já o Grupo de Cadeirantes Núcleo da Luz, vinculado à Fraternidade Cristã de Pessoas com Deficiência de Pelotas/RS é composto por oito integrantes. Desta integridade, seis membros aceitaram participar e colaborar com a pesquisa.

Referente às técnicas para coleta de dados, foram aplicados questionários a todos os sujeitos da pesquisa. Tal instrumento de coleta era composto de perguntas que visavam traçar o perfil dos respondentes (participantes cegos são todos turistas enquanto participantes cadeirantes são todos moradores de Pelotas), questões relacionadas ao entendimento das temáticas hospitalidade e hospitalidade urbana, assim como questões sobre a hospitalidade urbana da cidade de Pelotas/RS.

Quanto à coleta de dados, primeiramente foi feito um contato com os participantes por meio das redes sociais (Facebook e WhatsApp) para verificar a disponibilidade de colaborar com a pesquisa e deixá-los cientes sobre os objetivos e a proposta do estudo. A coleta dos dados com os participantes com deficiência visual se deu de duas maneiras: i) envio de um arquivo de texto (software Microsoft Word, o qual permite o uso de ferramentas de leitura de voz, que para pessoas com deficiência visual facilita o entendimento e a resolução das perguntas) por e-mail para um participante e ii) envio das perguntas via aplicativo WhatsApp - o qual permite uma maior praticidade e facilidade de respostas - para oito participantes. Nesta última, as perguntas foram enviadas e quatro participantes as responderam de forma escrita e os outros quatro responderam por mensagens de áudio. Já a coleta dos dados com as pessoas cadeirantes foi feita pela rede social Facebook - para coletar os dados de três participantes - e aplicativo WhatsApp - para coletar os dados de três outros respondentes os 
quais, neste caso, responderam por mensagens de áudio. O período de coleta de dados com as pessoas com deficiência visual foi entre abril e maio de 2019 e com as pessoas cadeirantes foi em maio de 2019.

Com isso, após o recebimento das respostas de todos os participantes, para tratamento e análise dos dados, se fez necessário a transcrição literal das respostas recebidas por mensagens de áudio. Depois de todas as respostas transcritas, os dados foram analisados pelo seu conteúdo. As respostas foram agrupadas de acordo com suas semelhanças e diferenças dentro dos temas analisados (hospitalidade, hospitalidade urbana e Pelotas hospitaleira). Ademais, foram utilizados referenciais teóricos sobre hospitalidade e acessibilidade (com foco para pessoas com deficiência visual e pessoas cadeirantes) a fim de que dialogassem com os resultados encontrados. Também foi utilizada a técnica nuvem de palavras ${ }^{2}$, a qual consiste em agrupar hierarquicamente termos de acordo com a frequência que aparecem nas respostas.

Por uma questão de organização e para facilitar a leitura e compreensão dos resultados, os participantes com deficiência visual foram identificados como "Respondentes CE" - abreviação para a palavra cegos - e os participantes com deficiência física foram identificados como "Respondentes CA" - abreviação para a palavra cadeirantes.

\section{RESULTADOS E DISCUSSÕES}

\subsection{Entendimento sobre hospitalidade}

A Figura 1 mostra um panorama a respeito do entendimento dos sujeitos sobre hospitalidade. Ao decorrer da seção e a partir dos relatos o assunto será mais detalhado.

Figura 1 - Entendimento dos sujeitos sobre hospitalidade

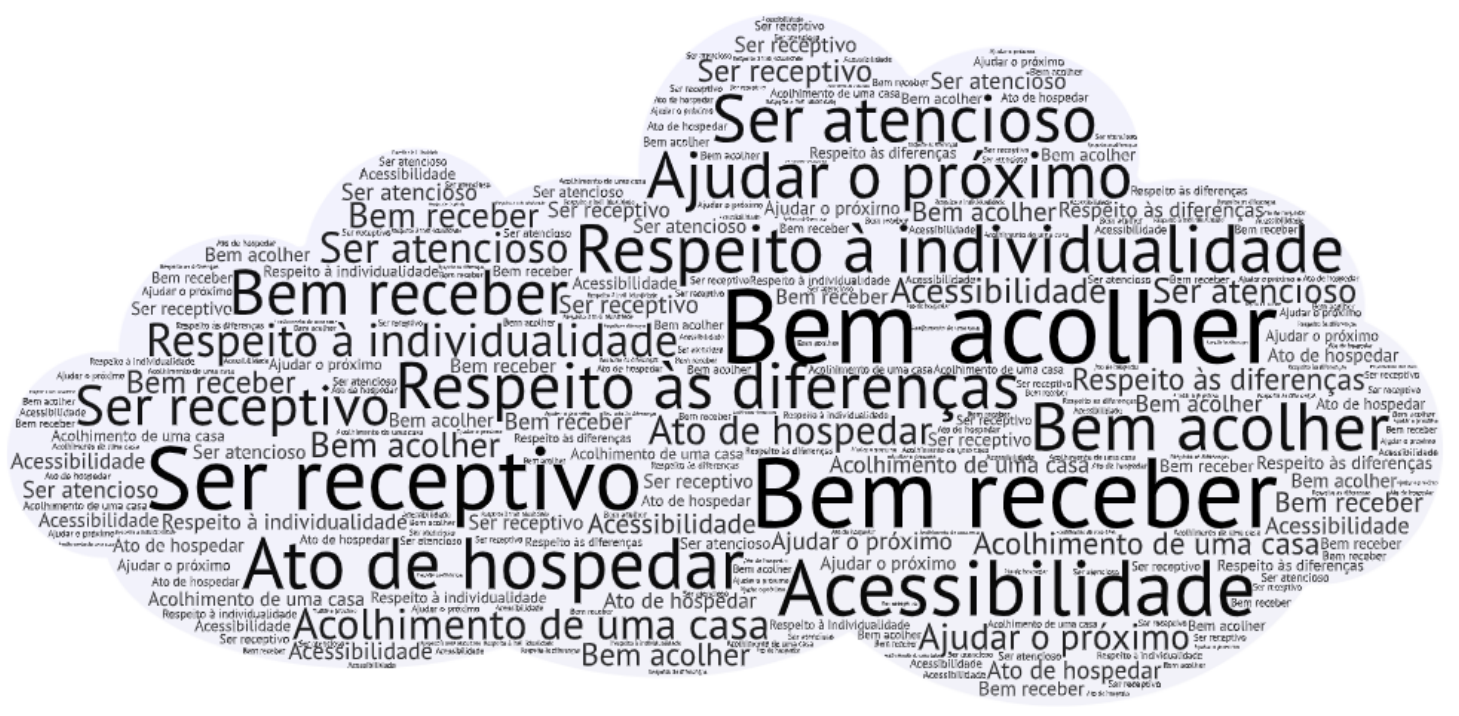

Fonte: Elaborado pelos autores com dados da pesquisa, 2020.

\footnotetext{
${ }^{2}$ Wordart.com - Acesso em 20 de agosto de 2020.
} 
Sobre o entendimento das pessoas com deficiência visual a respeito do tema hospitalidade, todos os participantes relacionaram a temática com o "bem receber", "bem acolher", "ser receptivo" e com o "ato de hospedar". O entendimento dos participantes vai ao encontro de definições teóricas como a de Grinover (2007, p. 125) que diz que "a hospitalidade pressupõe a acolhida: [...] acolher é permitir, sob certas condições, a inclusão do outro no próprio espaço".

O Respondente CE1 afirma: hospitalidade tem muito a ver com a recepção das pessoas, como trata-las bem, respeitando as diferenças no tocante a crenças, a religiões, a questões sociológicas e sem julgar [...], é uma questão de cuidado, atenção com o próximo. $\mathrm{O}$ Respondente CE8 complementa: "a hospitalidade está no respeito à individualidade de cada um". Essa questão ainda é reforçada pelo Respondente CE7, relatando que "hospitalidade tem relação direta com o bem-estar, acolhimento e respeito com o visitante". Tais relatos vão ao encontro conceitual descrito por Plentz (2005, p. 8) o qual "a hospitalidade envolve trocas, encontros, o ato do ir e do vir, de receber e dar, do dom e da dádiva, entre seres humanos e não somente como meros atendentes e serviçais. É o respeito entre as pessoas como indivíduos".

O Respondente CE2 relata: "enquanto leigo nessa área do turismo, vamos dizer assim, pra mim é a forma de ser recebido, acolhido, enfim... de como o lugar e como as pessoas estão preparados para receber que vem de fora, né?”. Observa-se também, pelo Respondente CE9, a hospitalidade como "a maneira como somos recebidos e tratados pelas pessoas do local”. O fato das relações humanas serem mencionadas frequentemente pode estar associado à essência do ato de acolher, pois para Dencker (2004) a hospitalidade trata-se de um ato social, culturalmente construído.

No que tange ao entendimento das pessoas com deficiência física (cadeirantes) a respeito do significado de hospitalidade, os participantes abordaram a temática sob diferentes perspectivas. A hospitalidade foi relacionada pelo Respondente CA2 à questão genuína: "hospitalidade é viver a vida ajudando o próximo sem analisar a vida religiosa, financeira, racial, gênero sexual linguagem e outros". Verifica-se que as considerações deste respondente corroboram com as de autores como Mauss (2003) e Boff (2005) que associam a hospitalidade à reciprocidade, ao acolhimento e à troca genuína.

Já na perspectiva do Respondente CA4, a temática está relacionada à hospitalidade doméstica: "a hospitalidade corresponde a um local que reflita o acolhimento de uma casa". O Respondente CA3 demonstrou dúvida ao responder, e ainda, se a mesma estava relacionada ao ato de hospedar: 
Não sei bem o que quer dizer, mas eu creio que é eu me acomodar em um hotel ou ir visitar alguém na casa dele ou a visita vir na minha né? Daí eu me preparo para receber minha visita? Hospitalidade é isso? Hospedar? (Respondente CA3, 2019).

As ponderações deste respondente corroboram com Dias (2002) a qual aponta que a hospitalidade engloba virtudes como hospedar; acolher, ser gentil e generoso.

$\mathrm{Na}$ opinião dos Respondentes CA1, CA5 e CA6 a hospitalidade está associada à acessibilidade e o preparo da cidade para a recepção dos cidadãos. Neste sentido, o Respondente CA5 afirmou: "É ter acesso livre sem barreiras. É se sentir bem. Confortável". Por sua vez, o Respondente CA6, declarou: "ao meu ver, hospitalidade é a maneira como uma cidade, uma casa te recebe".

As colocações de grande parte dos respondentes corroboram com Grinover (2006) que é um dos vários autores que direcionam seus estudos para a hospitalidade e a hospitalidade urbana, e considera a acessibilidade como um item indispensável em suas análises. Para o autor, a acessibilidade se refere às possibilidades de acesso dos indivíduos a certas atividades ou serviços presentes na cidade, proporcionando a igualdade de oportunidades (Grinover, 2006).

É perceptível que tanto as pessoas com deficiência visual quanto as pessoas cadeirantes atribuem à hospitalidade distintas perspectivas. Todos os participantes relacionam a temática ao receber-acolher. Percebe-se que as pessoas com deficiência visual comentaram bastante a questão do respeito com o visitante/turista e que as pessoas cadeirantes acrescentaram a relação da hospitalidade à dimensão da acessibilidade. A partir da elucidação das narrativas, e conforme as palavras da Figura 1 percebe-se o caráter polissêmico que a hospitalidade possui.

\subsection{Hospitalidade urbana e cidade hospitaleira}

A Figura 2 mostra um panorama sobre o que os sujeitos entendem enquanto hospitalidade urbana e cidade hospitaleira. Ao decorrer desta seção e a partir dos relatos dos participantes o assunto será mais bem detalhado. 
Figura 2 - Entendimento dos sujeitos sobre hospitalidade urbana e cidade hospitaleira

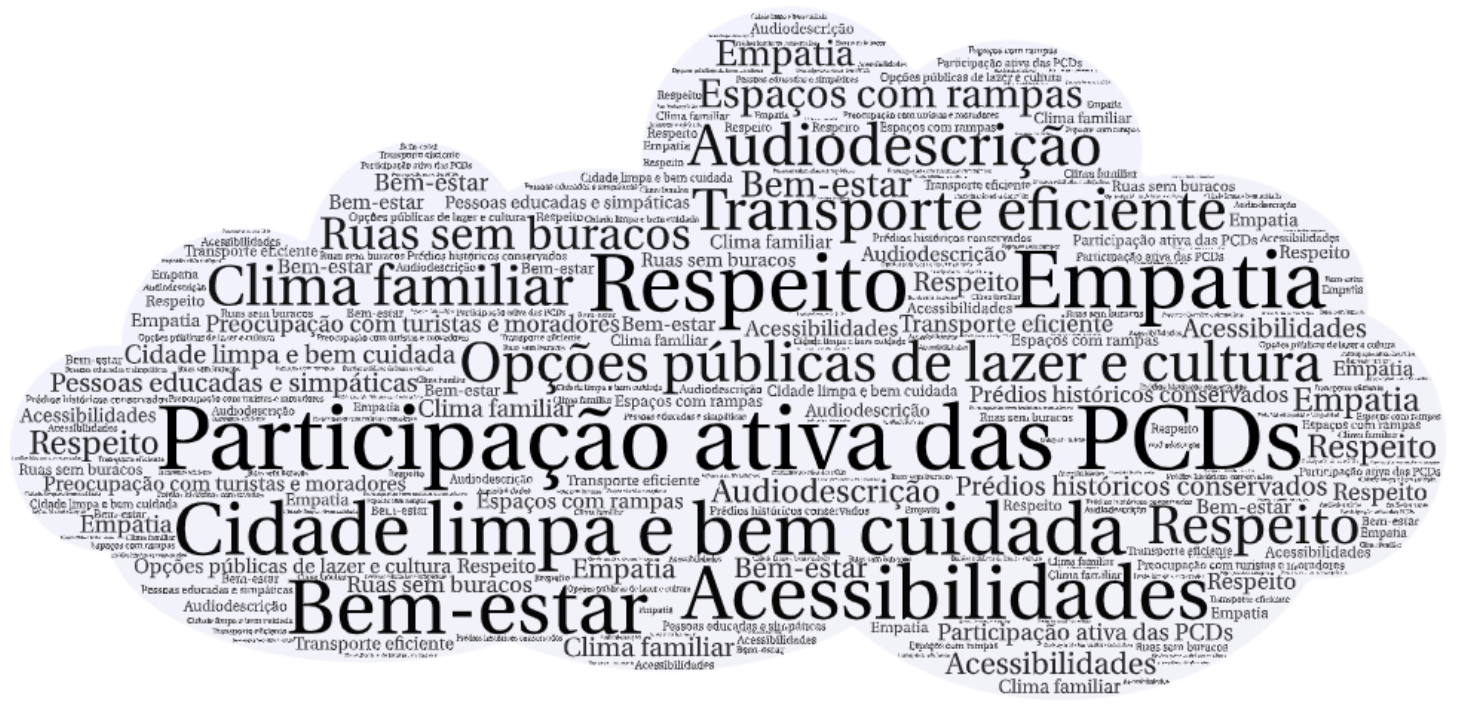

Fonte: Elaborado pelos autores com dados da pesquisa, 2020.

A vinda para uma nova cidade pode, a princípio, causar certo estranhamento, uma vez que "[...] cada um de nós sabe o que é chegar repleto de esperança e ao mesmo tempo de receio em uma cidade desconhecida, ser recebido por estranhos, reconhecer o traçado, entender a lógica e o significado dos fluxos" (Grinover, 2007, p. 16). A partir disto, no que tange as pessoas com deficiência visual, o Respondente CE1 relata que para uma cidade ser hospitaleira é necessário que "toda população entenda e respeite o visitante, inclusive criando um clima familiar".

O Respondente CE2 ressalta que "a cidade hospitaleira desperta uma espécie de familiarização e identificação com o local, desperta a vontade de voltar ao lugar, fazendo com que se fique com um registro afetivo positivo". Ambos os relatos remetem à questão da identificação com a cidade e com isso se faz interessante destacar a conceituação de Grinover (2007) a qual aponta a identidade como uma das três dimensões que compõem uma cidade hospitaleira. O Respondente CE5 entende por hospitalidade urbana:

\footnotetext{
$O$ quanto tu te sente participante naquele momento daquele espaço urbano. $O$ quanto tu transita e te sente a vontade e, não um ser fora do contexto. $O$ quanto então a gente é abraçado por esse espaço, acessível, com acolhimento e até com empatia (Respondente CE5, 2019).
}

Esta fala possui um significado tão forte e está diretamente ligada a ideia de ser uma pessoa, um ser ativo na cidade e para Silva $(2015$, p. 18) "a partir do momento em que os espaços urbanos recebem adequações para todos, transformam pessoas com deficiências em integrantes ativos na comunidade". Neste contexto, o Respondente CE4 conta: "hospitalidade urbana, para mim, seria uma cidade limpa, com várias opções públicas de lazer e cultura com acessibilidade. Para garantir hospitalidade a todos sem discriminar ninguém”. A partir 
dos comentários, é necessário entender que "para que o turismo represente uma parte do desenvolvimento e bem-estar integral das pessoas com deficiência, ele precisa ser realizado no mesmo espaço em que convivem as pessoas sem deficiência" (Mendes \& Paula, 2008, p. $330)$.

De maneira geral entre os participantes, destacaram-se questões estruturais como ruas e praças limpas e seguras, pisos regulares e transporte eficiente. O Respondente CE4 apontou que "prédios históricos preservados e abertos à visitação com guias para contar a história do lugar" também auxiliam a tornar uma cidade hospitaleira, principalmente, para as pessoas com deficiência visual.

A última fala aponta a importância da audiodescrição, principalmente para as pessoas com deficiência visual e Sacks (2010, p. 201) afirma que "a linguagem, a mais humana das invenções, pode possibilitar o que, em princípio, não deveria ser possível. Pode permitir a todos nós, inclusive os cegos congênitos, ver com os olhos de outra pessoa". A partir da audiodescrição, partes da cidade podem ser reconhecidas pelas pessoas com deficiência visual, o que faz parte da dimensão de legibilidade descrita por Grinover (2007) a qual se entende como a qualidade visual da cidade ou partes dela.

No que se refere à concepção de uma cidade hospitaleira para as pessoas com deficiência física (cadeirantes), todos os participantes mencionaram como prerrogativa a preparação e organização do espaço para usufruto dos cidadãos. Para o Respondente CA3, a cidade deve acolher a todos assim como cada indivíduo investe esforços para ser hospitaleiro com um hóspede em sua casa:

Eu arrumo a minha casa pra receber as visitas. Então a cidade também tem que
"tá" bonita. Por que no dia da Fenadoce a cidade fica toda bonita? Eu acho que
era pra ser sempre assim, limpa e bem cuidada, como se fosse a casa da gente, né?
(Respondente CA3, 2019).

A narrativa deste respondente corrobora com Esteves (2010) o qual aponta a limpeza e livre utilização do espaço urbano da cidade como elementos primordiais na concepção de uma cidade hospitaleira. Nessa linha de pensamento, o Respondente CA4 coloca que "uma cidade hospitaleira é aquela que se preocupa com seus turistas, que pensa em seu bem-estar, que se preocupa com todas as pessoas".

Ao mencionar atributos de uma cidade hospitaleira, os Respondentes CA3 e CA5 destacaram a limpeza como um item impossível de ser desconsiderado. No entanto, não se limitaram apenas a questão ambiental e visual. Em suas considerações, a acessibilidade física

\footnotetext{
${ }^{3}$ A Feira Nacional do Doce (Fenadoce) é um evento que conta o trajeto histórico dos doces pelotenses e integra as etnias responsáveis pela cultura doceira na região, atualmente está na $28^{\mathrm{a}}$ edição (Fenadoce, [20--]).
} 
também foi mencionada. Para estes respondentes se faz necessário “[...] boas ruas com rampas e sem buracos. Bons restaurantes, hotéis" (Respondentes CA3 \& CA5, 2019). As ponderações destes respondentes vão ao encontro de Silva (2010) o qual ressalta que o pouco investimento em adequações físicas como a inserção de rampas de acesso, sinalização adequada e equipamentos, não contribui para a autonomia dos cadeirantes.

Ao conceber a acessibilidade como um tópico relevante no tocante à hospitalidade, o Respondente CA1 ilustra dificuldades encontradas em seu cotidiano, mencionando que a cidade não prioriza o cuidado com esse grupo (cadeirantes): "A cidade precisa ter mais cuidados com os cadeirantes. Tem muitas lojas com araras de roupas nas portas, restaurantes, hotéis, lancherias e lan houses que não tem como chegar lá dentro" (Respondente CA1, 2019). A acessibilidade, uma das dimensões de análise de uma cidade hospitaleira se refere à possibilidade de acesso dos indivíduos a atividades e serviços da cidade (Grinover, 2006). No entanto, percebe-se que não é considerado por muitos (setor público e privado) como elemento crucial em seu planejamento.

Ainda em termos de acessibilidade, as considerações do Respondente CA6, identificam uma cidade hospitaleira como "[...] uma cidade que tem várias opções de lazer". Confirmando a ideia de Grinover (2006) que acessibilidade compreende também a possibilidade de acesso à cultura, informação e de frequentar um sistema de lazer.

Entre os atributos considerados pelos respondentes destaca-se também a educação. Segundo o Respondente CA2, compete a uma cidade hospitaleira "[...] a educação social que começa dentro da própria família e é completada dentro das escolas públicas e particulares". O ponto de vista deste respondente encontra apoio teórico nas considerações de Dutra et al. (2017) pontuam o elemento humano como importante ator do todo. Na concepção destes autores o indivíduo tem importante papel para que haja proximidade e estabelecimento de relações com o outro e com os lugares.

A Figura 3 apresenta algumas dimensões criadas a partir dos relatos dos participantes para que uma cidade seja hospitaleira para pessoas com deficiências. 
Figura 3 - Dimensões de uma cidade hospitaleira para pessoas com deficiências

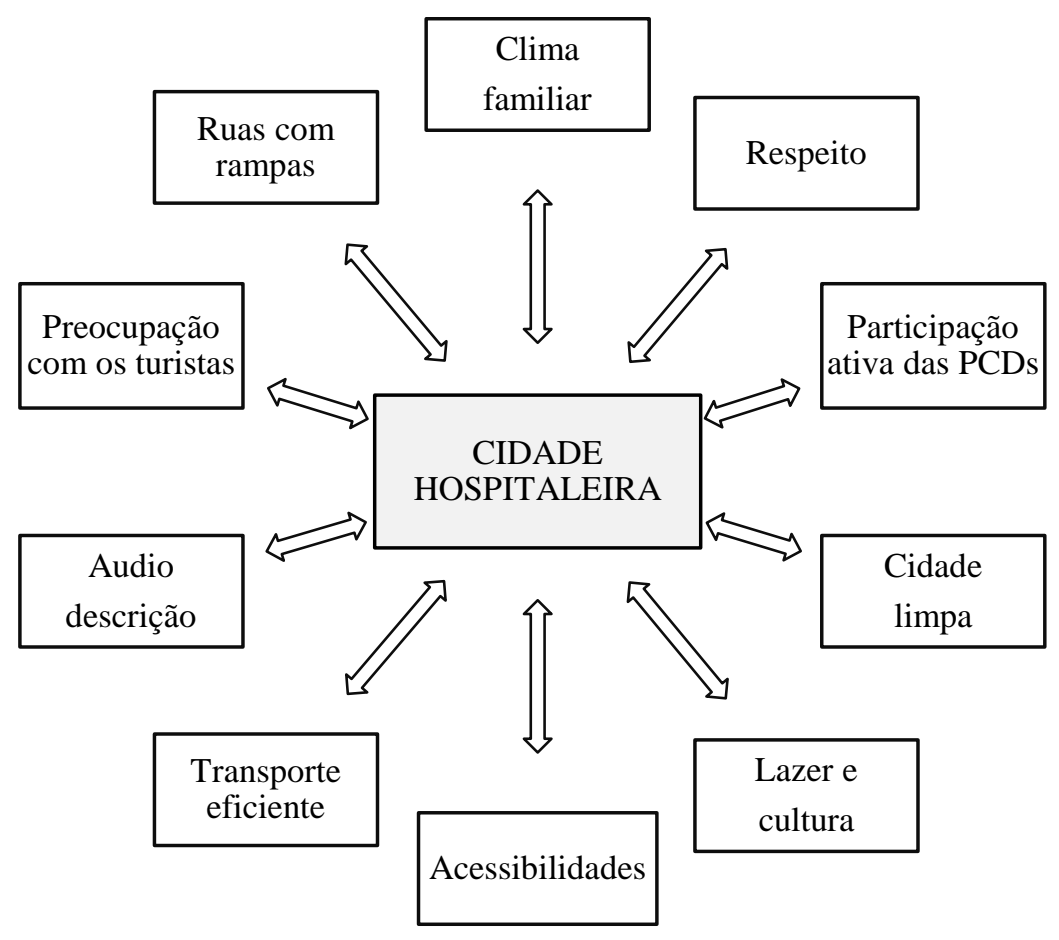

Fonte: Elaborado pelos autores com dados da pesquisa, 2020.

São perceptíveis algumas dimensões em comum entre os comentários a respeito da hospitalidade urbana e da cidade hospitaleira para as pessoas com deficiência visual e para as pessoas cadeirantes, quais sejam: respeito, preocupação e cuidado que a cidade deve ter com o cidadão (morador ou turista); lazer; e de uma maneira geral, dimensões estruturais também fazem parte deste rol. Percebe-se a dimensão da acessibilidade um pouco mais mencionada nas narrativas das pessoas cadeirantes e a dimensão da participação ativa e clima familiar com a cidade mais presente nos comentários das pessoas com deficiência visual.

\subsection{A hospitalidade de Pelotas/RS}

De acordo com o relato dos participantes com deficiência visual, Pelotas é considerada uma cidade hospitaleira, como o Respondente CE1 descreve:

a gente foi bem recebido em várias partes [...] na rodoviária, por exemplo, [...] e da pra perceber a evolução das pessoas, inclusive nas ruas, né? As pessoas cuidavam quando tinha uma pessoa com deficiência visual, o pessoal era bem atencioso (Respondente CE1, 2019).

Já o Respondente CE8 também relata afirmando que "os moradores e comerciantes ficam felizes em receber pessoas de outros lugares. Fica muito claro o orgulho dos pelotenses em mostrar as riquezas da cidade e sua história". E, com isso, o Respondente CE2 complementa dizendo: 
Definitivamente é (hospitaleira). Sempre fui muito bem atendido [...] tenho muitos amigos que moram em Pelotas e são pessoas muito receptivas, acolhedoras, muito afetivas e, para mim, sempre vinculei muito com a cidade, para mim isso é indissociável (Respondente CE2, 2019).

Percebe-se através dos relatos que as pessoas com deficiência visual participantes da pesquisa, possuem uma visão a respeito da cidade hospitaleira relacionando-a bastante com questões humanas, pessoais, e não somente ao espaço em si. Com isso, é possível associar os relatos à conceituação de Grinover (2007, p. 128) que afirma que atualmente "a cidade deixa de ser um conceito estritamente geográfico, para se transformar em um símbolo complexo e inesgotável da experiência humana".

Indo ao encontro de que Pelotas é uma cidade hospitaleira, o Respondente CE7 faz apenas uma ressalva: "talvez, ao passar informações sobre a cidade relacionadas ao turismo; cultura; história; falte um pouco de preparo, mas não é nada que cause má impressão". Porém, se faz necessário comentar que "oferecer e receber informação é um mecanismo de hospitalidade" (Grinover, 2007, p. 126). Nesse contexto, o Respondente CE8 salienta que "poderia ser melhor no quesito acessibilidade, principalmente na acessibilidade atitudinal". Sassaki (2009) afirma que a acessibilidade atitudinal é a supressão de atitudes preconceituosas, estigmatizantes, estereotipadas e discriminatórias.

Neste sentido, os Respondentes CE2 e CE3 revelam que possuíram pequenos problemas com transportes alternativos por aplicativos e com alguns comerciantes, respectivamente. Todavia salientam que foram situações pontuais que não interferiram em suas visões a respeito de Pelotas ser, de fato, uma cidade hospitaleira. Interessante destacar que anteriormente os comerciantes de Pelotas haviam sido elogiados pelo Respondente CE8 e para Plentz (2005, p. 5) essa discordância acontece porque "a hospitalidade possui um caráter subjetivo, ou seja, é inato, próprio de cada indivíduo e, por isso, difícil de ser mensurada".

Já as pessoas com deficiência física (cadeirantes), no que se refere à hospitalidade na cidade de Pelotas, possuem concepções diferentes sobre esta ser considerada hospitaleira. Os Respondentes CA2, CA3 e CA4 consideram-na hospitaleira, os Respondentes CA1 e CA5 a consideram hospitaleira em partes enquanto o Respondente CA6 não percebe Pelotas como um ambiente hospitaleiro.

Entre os respondentes os quais relacionaram a cidade de Pelotas como hospitaleira, o Respondente CA2 optou por não justificar sua resposta. O Respondente CA4, apesar de considerar a cidade hospitaleira declarou que há uma grande distância para alcançar o que seria o ideal sem ilustrar quais seriam as carências da cidade dizendo "acredito que ainda falta muito pra ficar cem por cento, mas ela está trabalhando para isso”. 
Casella (2006) ao abordar a hospitalidade nas cidades, pontua a importância de ações coletivas. Em sua concepção, é importante que o sentimento de coletividade e de responsabilidade compartilhada (sociedade e o poder público) seja uma realidade.

O Respondente CA3 foi o único que considerou Pelotas como hospitaleira e, de fato, apresentou motivos para tal mencionando "a disposição de variados espaços culturais, museus e parques". As considerações do Respondente CA3 reforçam o pensamento de Matheus (2002) que concebe as cidades hospitaleiras como espaços de liberdade e comunicação, com capacidade para receber e integrar seus moradores (temporários ou não).

Os Respondentes CA1 e CA5 os quais consideram Pelotas como hospitaleira em partes, destacam positivamente "o acolhimento aos turistas principalmente no evento Fenadoce" (Respondente CA5, 2019). Como aspecto não hospitaleiro foi mencionado à falta de estrutura física adequada para os cadeirantes: "sobre o lado não hospitaleiro: tem comércios que o cadeirante é esbarrado por uns degraus, escadas e rampas das beiras de calçadas que não são adequadas" (Respondente CA1, 2019). Na concepção de Merecci (2017) a hospitalidade só existe quando todos possuem acesso aos equipamentos, serviços e espaços.

O Respondente CA6 que assinalou não considerar Pelotas uma cidade hospitaleira, também mencionou a necessidade de melhorias estruturais: "Já melhorou um pouco, mas ainda faltam muitas coisas. Precisa de mais acesso nas ruas - como rampas -, lojas, bares, restaurantes, pizzarias, prédios públicos" (Respondente CA6, 2019). A narrativa deste respondente dialoga com Merecci (2017) e Aguirre (2003) que considera que a plena acessibilidade ao meio físico é uma das condições necessárias para igualdade de oportunidades a todos os indivíduos de uma comunidade.

As dificuldades enfrentadas pelos cadeirantes demonstram o quanto estes acabam sendo marginalizados pela sociedade, pois não conseguem gozar com autonomia e liberdade de espaços de uso coletivo. A Tabela 1 apresenta de maneira mais visual um copilado a respeito das percepções dos sujeitos sobre a concepção hospitaleira de Pelotas.

Tabela 1 - Percepções dos sujeitos referente a concepção hospitaleira de Pelotas/RS

\begin{tabular}{ccc}
\hline Sujeitos & Pelotas é hospitaleira? & Motivos \\
\hline \multirow{2}{*}{ Deficientes visuais } & Sim & $\begin{array}{c}\text { Atenção; cuidado; bom acolhimento; hospitalidade genuína. } \\
\text { Acessibilidade atitudinal; prestação de informações sobre a } \\
\text { cidade. }\end{array}$ \\
\cline { 2 - 3 } Cadeirantes & Sim & Bom acolhimento; variedade de espaços culturais. \\
& Não & Falta de acessibilidade física.
\end{tabular}

Fonte: Elaborado pelos autores com dados da pesquisa (2020). 
É perceptível que para todas as pessoas com deficiência visual, Pelotas é considerada uma cidade hospitaleira. As questões sobre relações humanas (receber-acolher) foram as mais citadas para elucidar a boa hospitalidade da cidade. Mesmo com algumas ressalvas, foram apontados diversos motivos os quais colocam a cidade no patamar de hospitaleira. Já para as pessoas cadeirantes houve divergência entre a concepção hospitaleira da cidade. Os cadeirantes explanaram a falta de acessibilidade como um dos principais motivos que os levam a não perceber Pelotas como hospitaleira em plena totalidade. Cabe destacar que as percepções dos participantes sobre a concepção hospitaleira (ou não) de Pelotas/RS vão ao encontro das palavras mencionadas em seus entendimentos sobre hospitalidade (Figura 1), hospitalidade urbana (Figura 2) corroborando com as dimensões sistematizadas pela pesquisa sobre uma cidade hospitaleira para pessoas com deficiências (Figura 3).

\section{CONSIDERAÇÕES FINAIS}

Respondendo a questão "como a hospitalidade da cidade de Pelotas/RS é percebida por pessoas com deficiências visual e física (cadeirantes)?" verificou-se que a hospitalidade da cidade de Pelotas/RS é percebida por pessoas com deficiências visual e física (cadeirantes) de formas diferentes. Para as pessoas com deficiência visual a hospitalidade está relacionada a questões humanas (acolhimento, respeito, empatia, etc.); a hospitalidade urbana está relacionada à como a cidade envolve o ser com deficiência visual em suas atividades; e mesmo com algumas ressalvas - todos os sujeitos consideraram Pelotas hospitaleira e elencaram alguns motivos para tal.

Já para as pessoas com deficiência física (cadeirantes), a hospitalidade está relacionada (além do bem receber) à questão da acessibilidade física; a hospitalidade urbana se aproxima à organização da infraestrutura e serviços urbanos para usufruto com autonomia e segurança; e a falta de acessibilidade física apareceu como o fator crucial para que metade dos sujeitos não atribuísse o ambiente hospitaleiro à cidade de Pelotas.

A invisibilidade das pessoas com deficiências nas atividades sociais (dentre elas o turismo) é algo ainda bastante presente. Com isso, este estudo demonstrou alguns aspectos que são considerados como não hospitaleiros assim como aqueles que são considerados inclusivos para pessoas com deficiências (visual e física) no que diz respeito à relação entre hospitalidade urbana e turismo.

Ao pensar na aproximação de pessoas com deficiências no turismo, geralmente, a acessibilidade física é mencionada. Em partes, isto foi comprovado nesta pesquisa com os sujeitos cadeirantes, entretanto a questão atitudinal (questões humanas) foi mais significativa 
do que aspectos físicos para os sujeitos com deficiência visual. Com este estudo observa-se que negar a participação de pessoas com deficiência nas atividades turísticas porque o ambiente/cidade não possui estrutura física para isto, não deve ser considerado aceitável para determinados grupos de pessoas com deficiência.

Teoricamente, esta pesquisa contribui com a sistematização de dimensões que formam uma cidade hospitaleira para pessoas com deficiências (visual e física) fomentando a discussão entre a interface conceitual das temáticas turismo, hospitalidade urbana e pessoas com deficiência e também aponta para um debate sobre uma possível hospitalidade acessível.

Além disto, como contribuição a pesquisa indica que gestores públicos atentem para as necessidades das pessoas com deficiências no que diz respeito à construção de uma cidade fisicamente mais inclusiva; empresas pensem cada vez mais em capacitar e treinar seus colaboradores para um atendimento mais acolhedor às pessoas com deficiência. E, especificamente no caso de Pelotas, que a cidade está no caminho certo quanto ao atendimento acolhedor, porém ainda é necessário que sejam pensados projetos e iniciativas que aprimorem a estrutura física da cidade para o aproveitamento e inclusão destas pessoas com deficiências (visual e física).

O fato de abordar a perspectiva de dois grupos distintos de pessoas com deficiência (visual e física) apresenta uma contribuição ainda pouco explorada pelas pesquisas em turismo e hospitalidade. Dessa forma, contribui para demonstrar que mesmo com dificuldades estas pessoas querem e estão participando das atividades turísticas, porém é necessário que o processo de inclusão seja acelerado para se tornar mais justo a todos. Mesmo tendo como limitação o fato de não termos obtido o envolvimento e colaboração da totalidade dos sujeitos, acredita-se que o objetivo desta pesquisa foi atingido e, ainda, sugere-se que este estudo seja aplicado também a pessoas com deficiência auditiva e/ou intelectual no intuito de averiguar as percepções e necessidades destes grupos em específico.

\section{REFERÊNCIAS}

Aguirre, R. S. (2003). Recreação e turismo para todos. Caxias do Sul, RS: Educs.

Boff, L. (2005). Virtudes para um outro mundo possível: Hospitalidade: direito e dever de todos. Petrópolis, RJ: Vozes.

Camargo, L. O. L. (2003). Os domínios da hospitalidade. In: Dencker, A., \& Bueno, M. (Orgs.). Hospitalidade: cenários e oportunidades. São Paulo, SP: Thompson.

Camargo, L. O. L. (2004). Hospitalidade. São Paulo, SP: Aleph. 
Camargo, L. O. (2015). Os interstícios da hospitalidade. Revista Hospitalidade, XII (especial), 42-69.

Camargo, L. O. L. (2019). Hospitalidade, turismo e lazer. Revista Brasileira de Pesquisa em Turismo, 13(3), 1-15.

Cambiaghi, S. (2007). Desenho universal: métodos e técnicas para arquitetos e urbanistas. São Paulo, SP: Senac.

Campos, S. R. (2008). Os cinco sentidos da hospitalidade. Observatório de Inovação e Turismo - Revista Acadêmica, 3(1).

Cantarelli, E. M. B. (1998). Barreiras sócio-culturais e lazer das pessoas portadoras de deficiência física: um estudo do grupo Fraternidade Cristã de Doença e Deficiência de Campinas, SP. Dissertação de Mestrado, Universidade de Campinas, Campinas, SP. Recuperado de http://repositorio.unicamp.br/jspui/handle/REPOSIP/274874

Casella, L. L. C. (2006). Hospitalidade dos espaços públicos: possibilidades e dificuldades em torná-lo acolhedor. Revista Hospitalidade, III(1), 35-46.

Darcy, S., \& Dickson, T. J. (2009). A whole-of-life approach to tourism: The case for accessible tourism experiences. Journal of Hospitality and Tourism Management, 16(1), 3244.

Dencker, A. F. M. (2004). Planejamento e gestão em turismo e hospitalidade. São Paulo, SP: Thomson.

Dias, C. M. M. (2002). Hospitalidade: reflexões e rerspectivas. São Paulo, SP: Manole.

Duarte, D. C., Pereira, J. C. R., \& Lima, K. S. C. (2016). A hospitalidade para deficientes visuais: um estudo nos setores hoteleiros sul e norte de Brasília - DF. In: Anais do XIII Seminário da Anptur. São Paulo, SP, Brasil.

Dutra, C. O., Caldas, L. C., Pinheiro, P. M. S., \& Bastos, T. R. (2017). Hospitalidade urbana do centro histórico de Pelotas/RS. Applied Tourism, 2(3), 79-93.

Esteves, F. V. (2010). Hospitalidade turística urbana com ótica no centro da cidade de Niterói-RJ. Trabalho de Conclusão de Curso, Universidade Federal Fluminense, Niterói, RJ, Brasil. Recuperado de https://app.uff.br/riuff/handle/1/1545

Fenadoce. ([20--]). História da feira. Recuperado de http://fenadoce.com.br/index.php/historia/

Ferraz, V. S. (2013). Hospitalidade urbana em grandes cidades. São Paulo em foco. Tese de Doutorado, Faculdade de Arquitetura e Urbanismo, Universidade de São Paulo - USP, São Paulo, SP, Brasil. Recuperado de www.teses.usp.br

Grinover, L. (2006). A hospitalidade urbana: acessibilidade, legibilidade e identidade. Revista Hospitalidade, III(2), 29-50.

Grinover, L. (2007). A hospitalidade, a cidade e o turismo. São Paulo, SP: Aleph.

Instituto Brasileiro de Geografia e Estatística - IBGE. (2010). Censo demográfico: Resultados gerais da amostra. Recuperado de 
https://www.ibge.gov.br/estatisticas/sociais/populacao/9662-censo-demografico2010.html?edicao $=9749 \& \mathrm{t}=$ destaques

Instituto do Patrimônio Histórico e Artístico Nacional - IPHAN. (2018). Notícias - IPHAN Rio Grande do Sul. Recuperado de http://portal.iphan.gov.br/rs/noticias/detalhes/4652/conjunto-historico-de-pelotas-rs-agora-epatrimonio-cultural-do-brasil

Luiz, J. S. (2016). Percepção da acessibilidade: uma comparação de alguns atrativos da cidade de Málaga (Espanha) e Rio de Janeiro (Brasil). Trabalho de Conclusão de Curso, Universidade Federal Fluminense, Niterói, RJ, Brasil.

Martins, P. I. S. R. (2008). A Inclusão pela Arte: Museus e Públicos com Deficiência Visual. Dissertação de Mestrado, Faculdade de Museologia e Museografia, Universidade de Lisboa, Lisboa, Portugal. Recuperado de http://hdl.handle.net/10451/647

Matheus, Z. M. (2002). A ideia de uma cidade hospitaleira. In: Dias, C. M. M. (Org.). Hospitalidade Reflexões e Perspectivas. São Paulo, SP: Manole.

Mauss, M. (2003). Sociologia e Antropologia. São Paulo, SP: Cosac \& Naify.

Mendes, B. C., \& Paula, N. M. (2008). A hospitalidade, o turismo e a inclusão social para cadeirantes. Revista Turismo em Análise, 19(2), 329-343.

Merecci, A. M. S. (2017). Acessibilidade do cadeirante no Centro Cultural Solar do Jambeiro. Trabalho de Conclusão de Curso, Universidade Federal Fluminense, Niterói, RJ, Brasil. Recuperado de https://app.uff.br/riuff/handle/1/4726

Mora, A. B. (2012). Design Inclusivo Centrado no Usuário: Diretrizes para ações de inclusão de pessoas cegas em museus. Dissertação de Mestrado em Design, Universidade Federal do Rio Grande do Sul, Porto Alegre, RS, Brasil. Recuperado de http://hdl.handle.net/10183/75770

Moreira, M. M. (2008). A inclusão de pessoas com deficiência pelo turismo: a democratização de benefícios na atividade turística. In: Anais do V SEMINTUR. Caxias do Sul, RS, Brasil.

Panosso Netto, A., \& Lohmann, G. (2012). Teoria do turismo: conceitos, modelos e sistemas. São Paulo, SP: Aleph.

Pasped. ([20--]). Movimento Fraternidade Cristã. Recuperado de http://pasped.org.br/movimento-fcd/\#Nucleos

Perazzolo, O. A., Pereira, S., \& Santos, M. M. C. (2013). Acolhimento e desenvolvimento socioturístico: para uma psicopedagogia do laço social. In: Anais do X Seminário da Anptur. Caxias do Sul, RS, Brasil.

Pereira, L., Degasperi, M. H., \& Couto, D. (2018). 'Olho de Sogra': patrimônio e mediações culturais acessibilizadas em Pelotas. In: Anais do VI ENAC. Rio de Janeiro, RJ, Brasil.

Peres, J., V. (2018). Vamos compartilhar a cidade: uma análise sobre a hospitalidade em Pelotas/RS. Trabalho de Conclusão de Curso, Graduação em Bacharelado em Turismo, Universidade Federal de Pelotas, Pelotas, RS, Brasil. Recuperado de http://pergamum.ufpel.edu.br:8080/pergamumweb/vinculos/0000bb/0000bb56.pdf 
Plentz, R. S. (2005). O papel da hospitalidade na busca de um outro turismo. In: Anais do III SEMINTUR. Caxias do Sul, RS, Brasil.

Ribas, J. B. C. (1985). O que são pessoas deficientes? São Paulo, SP: Brasiliense.

Rodrigues, I. M. (2019). Hospitalidade pelotense pela visão de quem não enxerga. Trabalho de Conclusão de Curso. Graduação em Bacharelado em Turismo, Universidade Federal de Pelotas, Pelotas, RS, Brasil.

Santos, M. M. C., \& Perazzolo, O. A. (2012). Hospitalidade numa perspectiva coletiva: o corpo coletivo acolhedor. Revista Brasileira de Pesquisa em Turismo, 6(1), 3-15.

Sacks, O. (2010). O olhar da mente. São Paulo, SP: Companhia das Letras.

Sassaki, R. K. (2003). Inclusão no lazer e turismo: em busca da qualidade de vida. São Paulo, SP: Áurea.

Sassaki, R. K. (2006). Inclusão: construindo uma sociedade para todos. Rio de Janeiro, RJ: WVA.

Sassaki, R. K. (2009). Inclusão: acessibilidade no lazer, trabalho e educação. Revista Nacional de Reabilitação (Reação), XII, 10-16.

Severini, V. F. (2013). Hospitalidade urbana: ampliando o conceito. Revista Iberoamericana de Turismo - RITUR, 3(2), 84-99.

Silva, L. A. (2010). Acessibilidade em museus e espaços culturais: estudo técnico sobre a edificação histórica que irá abrigar a Fundação Hansen Bahia, na cidade de cachoeira-BA. Trabalho de Conclusão de Curso, Graduação em Museologia, Universidade Federal do Recôncavo da Bahia, BA, Brasil. Recuperado de http://hdl.handle.net/123456789/2004

Silva, M. C. N. (2015). Acessibilidade para Deficientes Visuais: Um Estudo em Atrativos Turísticos de Natal/RN. Trabalho de Conclusão de Curso, Graduação em Turismo, Universidade Federal do Rio Grande do Norte, Natal, RN, Brasil. Recuperado de http://monografias.ufrn.br/handle/123456789/4868

Tribe, J. (2010). Tribes, territories and networks in the Tourism Academy. Annals of Tourism Research, 37(1), 7-33.

\section{FORMATO PARA CITAÇÃO DESTE ARTIGO}

RODRIGUES, I. M., MINASI, S. M., LOPES, A. I., \& SILVA, L. S. (2021). A hospitalidade de Pelotas/RS pela visão de quem não enxerga e aos passos de quem não caminha. Revista de Turismo Contemporâneo, 9(2), 230-251. https://doi.org/10.21680/2357-

$\underline{8211.2021 v 9 n 2 I D 23613}$ 